\title{
William Faulkner: La guerra es un negocio
}

\author{
Alejandro ARROYo FERNÁNDEZ \\ Departamento de Filología Inglesa \\ Universidad Complutense de Madrid \\ alejandro_arrofer@hotmail.es
}

\begin{abstract}
RESUMEN
El condado de Yoknapatawpha muestra el desarrollo de Estados Unidos desde un sistema tradicional de estructura patriarcal relacionado con el entorno natural y rural, a una sociedad contemporánea desarrollada en el ámbito socio-económico cercana al capitalismo. El contexto histórico y el marco socio-económico son elementos compositivos básicos en la literatura faulkneriana. Los efectos y consecuencias de la Guerra de Secesión y la Primera y la Segunda Guerra Mundial resultan fundamentales para establecer un paralelismo entre la evolución de la comunidad sureña y la nación americana. William Faulkner crea un microcosmos representativo de la historia americana.
\end{abstract}

Palabras clave: guerra, ética, sistema, riqueza, poder.

\section{William Faulkner: The War is a Business}

\begin{abstract}
Yoknapatawpha is a fictional county created by William Faulkner that represents the evolution of the United States. It shows the development of the nation, from a traditional system defined by a patriarchal structure and that is deeply related to the rural environment, to a modern society whose socioeconomic system is close to the capitalism. The faulknerian literature will use the most relevant events of the American history to recreate a community whose economic system has been strongly influenced by the Civil War, the World War I and the World War II.

These struggles are faulknerian literary elements that prove that his fictional southern community evolves in parallel to the American nation.
\end{abstract}

Keywords: war, ethic, system, richness, power.

\section{Formación del condado}

Antes de abordar la influencia que ejercen los conflictos bélicos en el marco socio-económico norteamericano hay que retratar la estructura social. Tradicionalmente el sistema de regulación dependía de las familias poderosas de la comunidad, 
de sus negocios, de su potencial económico y, en la mayoría de los casos, de su arraigue a la historia del condado por haberlo heredado generacionalmente. Este hecho conforma la base de obras emblemáticas del autor sureño como The Sound and the Fury, Sartoris y Absalom, Absalom! mostrando cómo el líder familiar es el regente de la comunidad. Existen varias estrategias para mantener el liderazgo del espacio como, por ejemplo, las relaciones incestuosas y la repetición de los nombres para conseguir una ligazón entre el territorio y un individuo en particular, tal y como representan Jason Compson IV en The Sound and the Fury o John Sartoris en Sartoris.

La trilogía de los Snopes muestra cómo el modelo tradicional es desbancado en favor de la modernidad relatando la llegada de la familia Snopes desde el norte de la nación y su paulatino ascenso. Su incursión origina modificaciones en el sistema socio-económico que desligan la comunidad del sistema de explotación tradicional. La ocupación de puestos relevantes, como el banco o la gerencia del hotel, junto con los matrimonios de conveniencia, conforman su estrategia de ocupación y dominio. De hecho, The Hamlet, primera parte de la trilogía, retrata la caída de Varner y el ligero despertar Snopes a través de esa obtención sigilosa y continua de poder. Yoknapatawpha es un ente orgánico que considera que los Snopes son una plaga, un virus que infecta y somete, y deberían ser repudiados por su condición de extranjeros. No obstante, la inteligencia de Flem Snopes marcará los designios del enclave ya que su ascenso lidera el crecimiento y la estabilidad del clan.

La narración en retrospectiva exige la recuperación del imaginario bélico relacionado con los herederos de la Guerra de Secesión y de la Primera Guerra Mundial. Reaparecen personajes faulknerianos icónicos aludiendo a acontecimientos pretéritos para reconstruir la atmósfera a través de una voz que reproduce el mensaje de la comunidad. «He [the narrator] has not only a sense of community but also a sense of history» (Brooks 1978: 159). El sentido de historia favorece la comprensión del origen, progreso y meta de un lugar influido por el desarrollo idiosincrático de sus ciudadanos. The Hamlet está ambientada en 1930, es decir, en un periodo de entreguerras caracterizado por el ascenso y desplome de la economía norteamericana. Yoknapatawpha es un espacio vivo, que cambia y evoluciona, pero que, en algunos aspectos, está anclado al pasado porque todavía siguen presentes las huellas del combate, las cicatrices de la Guerra de Secesión que recuperan esa contienda fratricida entre los Estados americanos. La llegada de los Snopes y su enfrentamiento con la familia Varner por la dominación del territorio recrea alegóricamente esa lucha entre el ejército de la Unión y los Confederados porque el desenlace de la Guerra de Secesión es idéntico al de la trilogía, el Norte vence.

Si bien la tradición sureña establece la necesidad de una estructura familiar rígida que gobierne durante generaciones, la trilogía demuestra que Flem quiere ser el caudillo único, el regente, el líder de la comunidad. Inicialmente se remarca el gran número de miembros del clan Snopes y su expansión por la comunidad es una niebla que cubre el entorno y se intercala en las capas del sistema socio-económico. Sin embargo, Flem se deshace gradualmente de sus familiares, algunos son encarcelados y otros expulsados debido a sus prácticas ilegales o amorales. El autor se distancia de su propia figura pública recuperando ese orgullo sureño para destacar simbólicamente la avaricia y el oportunismo de los Estados del norte tras su victoria en 
la Guerra de Secesión. Faulkner aparta momentáneamente su rol de creador permitiendo que sea el joven William, el descendiente del Coronel Clark Falkner, el que detalle la debacle sureña.

En definitiva, Yoknapatawpha es una alegoría de la historia de Estados Unidos y la literatura faulkneriana muestra su desarrollo en materia socio-económica, su progreso desde un sistema de explotación tradicional a una sociedad cercana al capitalismo. La modificación de la nación está ligada a los conflictos bélicos americanos y sus descendientes, sus triunfadores y vencidos, se convierten en una representación del ascenso y la debacle de la nación.

\section{Las repercusiones en el ámbito socio-económico}

Tras haber establecido en el bloque anterior la existencia de un clan familiar representante del sistema socio-económico y cómo su patriarca se autoproclama líder de la comunidad durante generaciones, cabe preguntarse cómo se produce su ascenso y asentamiento. William Faulkner crea un eje cronológico relacionando los conflictos bélicos de Estados Unidos, especialmente la Guerra de Secesión y la Primera y Segunda Guerra Mundial, y su repercusión en la bonanza y decadencia de la nación.

Existe un nexo entre los clanes faulknerianos dominadores del condado y la Guerra de Secesión (1861-1865) en The Sound and the Fury (1929) y Absalom, Absalom! (1935). La influencia y el control que ejercen la familia Compson y Thomas Sutpen, unido al hecho de que sean representantes del sistema tradicional sureño, favorece que Faulkner recurra a ellos cuando desee recuperar el imaginario histórico.

El segundo evento bélico reseñable en este acercamiento analítico es la Primera Guerra Mundial ya que sus repercusiones se observan en Soldier's Pay (1926), Sartoris (1929), Pylon (1935), The Hamlet (1940) y A Fable (1954). El autor expone dos influencias contrapuestas del conflicto en la nación americana porque mientras que Soldie's Pay y Pylon demuestran cómo la guerra destruye al individuo, The Hamlet sugiere el enriquecimiento de los Snopes a su término porque en el periodo de entreguerras se produce su llegada al condado. Flem utiliza ese sentimiento de bonanza económica y riqueza generalizada para conseguir el poder y, en el cierre de la novela, hace creer a Armstid y Ratliff que existe un tesoro oculto. La avaricia es derrotada por su suspicacia e inteligencia, se describe a sus dos rivales cavando desesperadamente para encontrar un botín inventado. Esta artimaña triunfa porque el crecimiento de la nación propicia que se crea en la existencia de dichas fortunas. Asimismo, Sartoris presenta la faceta enriquecedora de la Primera Guerra Mundial para Estados Unidos y, al mismo tiempo, la destrucción psicológica individual con la figura de un joven Sartoris incapaz de recuperarse anímicamente tras el fallecimiento de su hermano en dicho enfrentamiento.

Las novelas están ligadas a un eje cronológico de base socio-económica e histórico-cultural que delinea el desarrollo de la comunidad. De hecho, la familia Compson progresa gracias a una explotación agrícola que se ampara en las leyes escla- 
vistas, al igual que hace Thomas Sutpen en Absalom, Absalom!, para edificar su imperio. Este despotismo, y otros factores culturales y financieros, desencadenan la Guerra de Secesión modificando el organigrama financiero tras la abolición de la esclavitud y la industrialización.

El desarrollo técnico moderniza el país y favorece indirectamente su avance armamentístico y preparación para la Primera Guerra Mundial. Al concluir la misma, Estados Unidos disfruta de una mejora financiera que, lejos de ser beneficiosa, perjudica y envenena la sociedad, es la época dorada, es la década de 1920: «crash had its origins in the widespread optimism of the previous decade, and the sense that the country was entering an era of general prosperity» (Jenkins 2012: 201). La irresponsabilidad económica provoca el hundimiento de la bolsa poniendo fin al desarrollo económico. Autores como Scott Fitzgerald, con obras como The Great Gatsby (1925), plasman los peligros del despilfarro, el contrabando y la violación de la Ley Seca (1920-1933). Además, se produce el nacimiento de nuevos arquetipos como los gángsteres y las deseadas y sensuales flappers. Faulkner vincula las consecuencias de la guerra con la corrupción y podredumbre del sistema económico americano en Sanctuary (1931) donde la prostitución, el contrabando y los asesinatos protagonizan el goticismo de su atmósfera. La grandeza del país es dañina, nociva, y rezuma una oscuridad que demuestra la condena de su crecimiento por estar relacionado con un dinero podrido y manchado con la sangre de los combatientes que dieron su vida por salvaguardar la nación. La crudeza y la brutalidad de un sistema creado gracias a un conflicto bélico es evidente en Soldier 's Pay y Pylon porque muestran que los héroes de guerra no tienen lugar cuando regresan a su hogar. Pylon retrata una escena moderna y alejada de la tradición literaria faulkneriana donde los pilotos han sido reducidos a bufones aéreos que arriesgan su vida con acrobacias por un sueldo miserable. Su muerte no será más que una fría e inútil necrológica en un periódico porque su puesto es inmediatamente reemplazado por otro ente olvidado que se arriesga al mismo trágico final. La novela muestra los aspectos más nocivos de la sociedad moderna: «[...] the lack of community, the dullness and uniformity, the exploitation of the human beings» (Brooks 1978: 187). Esta opresión refuerza la dureza del sistema capitalista resultante de la Primera Guerra Mundial en Pylon exponiendo que la vida humana es un objeto perecedero. Yoknapatawpha les niega el heroísmo porque no les adjudica el suficiente reconocimiento y les convierte en soldados desconocidos. Hemingway insinúa en «Soldier's Home» (1925) que el héroe tiene una fecha de caducidad limitada al campo de batalla porque sus hazañas le proporcionan una fama que se erosiona paulatinamente hasta desaparecer.

El sistema financiero presente en la trilogía de los Snopes, especialmente en The Town y The Mansion, es una consecuencia de la Primera y la Segunda Guerra Mundial. La economía resulta un rasgo fundamental para la comunidad e influye en los estratos y componentes del sistema socioeconómico sureño. Wallstreet Panic Snopes es prueba evidente de este influjo pues su nombre está asociado al colapso bursátil de 1929. El carácter opresor del sistema y su escasa formación académica impiden que pueda reconocer las connotaciones negativas de su nombre. De hecho, tras descubrir que su figura está ligada alegóricamente al cataclismo económico de la 
nación decide cambiárselo por Wall Snopes. Esta ligera modificación le permite distanciarse de ese matiz nocivo e indica simbólicamente el deseo generalizado de escapar de un sistema opresor que obstaculiza el desarrollo individual.

El final de la trilogía muestra la culminación del proceso de supremacía con Flem trabajando en el banco dirigido por Will Varner, acontecimiento que remite a la familia Sartoris y a su manejo financiero en Jefferson en Sartoris. Así, William Faulkner hace honor a una de sus citas más célebres a través de la voz de Stevens «The past is never dead. It's not even past» para demostrar que el presente no es más que una repercusión del pasado. El tiempo es un instrumento, una herramienta de recreación histórica que establece un hilo argumental textual. El presente es una entidad temporal vacía, inexistente y sin valor, porque no es más que una consecuencia del pasado y una proyección del futuro. Este flujo temporal facilita la repetición de los acontecimientos y es la herramienta narrativa faulkneriana de conexión textual, ya que los detalles omitidos de sus novelas son desvelados desde otros textos. Así, The Town y The Sound and the Fury están conectadas a pesar de haber sido publicadas con treinta años de distancia porque The Town explica cómo Jason vende los últimos terrenos de la familia Compson. Este negocio relaciona la historia del condado a través de dos clanes representativos, la sustitución de la esencia tradicional de la comunidad por la modernidad, y los textos con el marco histórico-cultural pues esos terrenos se utilizan para la construcción del aeropuerto «Eula Acres», al servicio de la nación durante la Segunda Guerra Mundial. En cierto modo, Jason une a través de las finanzas la Guerra de Secesión y la Segunda Guerra Mundial, y Flem muestra la visión económica del choque bélico al enriquecerse con la explotación de esos terrenos. Todo está en venta. Hemingway en «War Medals for Sale», recogido en el periódico The Toronto Star Weekly el 8 de diciembre de 1923, insinúa el escaso valor cualquier elemento relacionado con la Primera Guerra Mundial. Hemingway visita varias casas de empeños para vender las medallas de guerra pero las rechazan porque únicamente interesan las que son de plata. El honor y el coraje no valen nada en la comunidad moderna americana.

Por último, cabe resaltar que la guerra no se presenta únicamente como una herramienta de consolidación social porque, en algunos casos, permite la instrucción ética y moral del individuo. Se menciona la Guerra Civil Española en The Mansion al sugerir que Kohl, el marido de Linda Snopes, fallece en ella defendiendo los ideales republicanos, demostrando la necesidad de luchar contra el sistema en aras de conseguir la libertad. El conflicto español resulta interesante para el autor sureño y, a pesar de no haber acudido como hizo su contemporáneo, amigo y rival Hemingway, destaca su relevancia a través de Charles Mallison, narrador en la trilogía y que afirma que este es el germen de la Segunda Guerra Mundial. Faulkner encumbra la trascendencia de la Guerra de Secesión y la Primera Guerra Mundial para plasmar los aspectos más trascendentes del pasado y la Segunda Guerra Mundial para demostrar su influencia en el presente. La destrucción del sistema económico de Yoknapatawpha es inevitable porque se sustenta sobre tres conflictos bélicos de gran magnitud y se apoya en una base corrupta donde están presentes la esclavitud, el contrabando, la figura del gángster, la prostitución y la pornografía.

Resumiendo, existe un vínculo entre los conflictos bélicos norteamericanos y la evolución de la nación en materia socio-económica. Los textos están unidos entre sí 
en una estructura temporal de carácter cíclico donde el presente está vacío y no es más que una repercusión del pasado y una proyección del futuro. Todos los elementos textuales compositivos están ligados a través de un imaginario común favoreciendo que los textos trabajen como un todo, como una unidad orgánica, un microcosmos representativo de la historia de Estados Unidos.

\section{Erotismo bélico}

En los bloques anteriores se ha destacado cómo Faulkner crea una atmósfera que es una repercusión de los acontecimientos bélicos más reseñables de la historia de la nación y de la recuperación de un imaginario que muestra la evolución de la comunidad en materia económica. Cabe destacar que su posicionamiento con respecto a estos conflictos varía a lo largo de su vida. La Primera Guerra Mundial es una oportunidad para satisfacer su egoísmo, para convertirse en un héroe de la comunidad, en un paladín que sigue la estela de su abuelo Clark Faulkner en la Guerra de Secesión. Por otro lado, la Segunda Guerra Mundial es solamente una herramienta para enriquecerse, es un elemento compositivo del marco histórico-cultural de sus novelas. Se distanciará de sus contemporáneos porque mientras que estos destacan los horrores y la destrucción del conflicto, Faulkner utilizará aspectos seductores de la batalla y confrontará la belleza femenina europea con la norteamericana.

Eula Varner destaca en Yoknapatawpha por ser una joven dominada por su parte dionisíaca y entregada al placer sin preocuparse por las repercusiones. Sus encuentros sexuales con el profesor Labove son extremadamente atractivos por ser un acto animal, placentero e inmoral. Su figura cautiva porque su posición social podría favorecer el ascenso de cualquier pretendiente en el organigrama de la ciudad. No obstante, lo realmente interesante es cómo sucumbe a un acto sexual, duro, prohibido y violento, desligándose de, en términos de Diane Roberts, la mujer confederada: «the Confederate Woman image allowed women to take on traditionally masculine roles with no sacrifice of what the culture identifies as essential white femininity: maternal feeling, sexual chastity, adherence to a male economy where property (land) is all-important» (1994: 3). Los personajes femeninos alejados del arquetipo faulkneriano tradicional y relacionados con el mantenimiento de la estructura familiar son castigados por seguir sus pulsiones sexuales. Su promiscuidad es sometida por la moral sexual cultural y por el marco de valores. Eula no es el único ente femenino regido por sus pulsiones sexuales pues Caddy en The Sound and the Fury y Charlotte en The Wild Palms se rigen por el mismo comportamiento. Eula se distancia de ellas porque es la única que permanece en la comunidad, aunque es abandonada cuando se queda embarazada. Curiosamente, este hecho provocará la caída de los Varner porque Flem se hace responsable de ella y supone el comienzo del ascenso de su clan. Esta lujuria femenina sureña colisiona con el erotismo europeo que introduce Ward Snopes en The Town. Su participación amoral en la Segunda Guerra Mundial gira en torno a la avaricia y el enriquecimiento personal, de ahí que al regresar a Estados Unidos inaugure un negocio que oculta en su parte trasera el visionado clandestino de diapositivas eróticas robadas en Francia. La doble moral americana asegura la prosperidad del negocio porque, aunque 
es una actividad censurable, es uno de los lugares más concurridos de la ciudad y, a pesar de que su conducta colisiona con el marco ético, la fascinación que despierta la feminidad europea le exime de una condena pública. Flem encuentra en este negocio la oportunidad para deshacerse de Ward Montgomery Snopes y le acusa de contrabando tras colocarle furtivamente unos bidones con alcohol en su tienda. Evidentemente, Flem ataca a Ward porque puede arrebatarle el poder ya que su negocio es conocido en las altas esferas de la ciudad.

Tras presentar el deseo carnal en la figura de Eula y la feminidad y sensualidad de las mujeres europeas en las diapositivas de Ward, cabe resaltar el erotismo y poderío de la heroína de la trilogía, Linda. A pesar de ser hija biológica de Spain, es la heredera del clan Snopes y ayuda a Mink a asesinar a su padrastro Flem. Su erotismo se relaciona con su actitud luchadora e idealista, su capacidad y deseo de preservar la justicia, causando una fascinación que despunta en ese decrépito ambiente. Su cercanía al abogado Stevens muestra su necesidad de rodearse de individuos instruidos y éticos. Linda abandona Yoknapatawpha para luchar contra las injusticias y buscando nuevos ideales con los que construir su futuro. Su unión con Kohl, el artista de ascendencia judía, indica su deseo de distanciarse del Sur, de ese lugar anclado al pasado, a ese tiempo pretérito vivo que crea un futuro inexistente.

Como se ha mencionado anteriormente, en este periodo William Faulkner no siente la necesidad de convertirse en héroe, no ansía ser el líder de la comunidad, solo desea prosperar económicamente. Se aleja notablemente de Europa y se rinde a la vida disoluta que le ofrecen Hollywood y estrellas de la época como Hoagy Carmichael, Lauren Bacall y Humphrey Bogart tras convertirse en guionista para Warner Bross. Sin embargo, autores como Hemingway buscan el erotismo europeo y la belleza femenina en tiempos de guerra:

It's all lemon orchards and orange groves along the right-hand side of the railway, and so pretty that it hurts to look at it. Hills terraced and yellow fruit shining through the green leaves and darker green of olive trees on the hills and streams on the hills, and streams with wide dry pebbly beds cutting down to the sea and old stone houses, and everything all color. (Hemingway 2014: 9)

La presentación de este paraíso terrenal transforma la escena y difumina la rudeza del soldado mostrando su vena más poética y sensible. La violencia del enfrentamiento es irrelevante al entrar en escena uno de los iconos de la sensualidad americana de la literatura del siglo XX, es decir, la joven mujer europea de belleza hasta entonces desconocida:

After the meal, we sat out in the garden under the orange trees, jasmine matted on the walls, and the moon making all the shadows blue-black and her hair dusky and her lips red. Away off you could see the moon on the sea and the snow up on the shoulder of Aetna mountain. (Hemingway 2014: 10)

El individuo americano moderno está fascinado por la sensualidad que emana del viejo continente, por sus parajes, por sus mujeres, por esa oferta de libertad y conocimiento que ofrece Europa. 
Resumiendo, se observa que William Faulkner y Hemingway destacan la belleza y el erotismo de Europa y sus mujeres desde diferentes perspectivas. Si bien Hemingway está en el campo de batalla experimentando, sufriendo y relatando los horrores de la guerra, William Faulkner divaga y disfruta de una vida cómoda en Hollywood. La mujer europea es para Hemingway un oasis, un paraíso en el centro de la destrucción del mundo, mientras que Faulkner utiliza ese erotismo para ensuciar y desprestigiar al sistema americano pues, como se ha mencionado, la prostitución y promiscuidad están presentes en sus textos. Asimismo, la belleza de estas jóvenes es ensalzada por el sentimiento de soledad del soldado en el caso del Hemingway y, por lo inalcanzable que resultan debido a su estatus en el caso de Faulkner. Sin embargo, sus posicionamientos distantes no eliminan la base, el rasgo, el atributo de la mujer de las décadas de 1940 y 1950, su sensualidad y su erotismo.

\section{Conclusión}

Faulkner muestra un microcosmos caracterizado por un sistema socio-económico producto de las repercusiones de los grandes conflictos bélicos de Estados Unidos. Se puede trazar un eje bélico-económico que demuestra la influencia de la Guerra de Secesión y la Primera y la Segunda Guerra Mundial en su universo literario. Yoknapatawpha se comporta como un ente vivo que ejerce su hostilidad y agresividad contra aquellos que han participado en la guerra negándoles ese heroísmo que les pertenece legítimamente.

Por otro lado, se observa el desarrollo del sistema económico americano y cómo evoluciona desde un sistema tradicional hasta un protocapitalismo sustentado en la ocupación de los puestos más relevantes de la comunidad.

Por último, hay que resaltar el erotismo bélico, esa sensualidad que emana de Europa y sus mujeres para los norteamericanos incluso en tiempos de guerra. El acercamiento de los escritores hacia ese fenómeno varía en función de las intenciones personales porque, si bien otros autores lo retratan literariamente en primera persona, Faulkner utilizará ese atractivo para la creación de sus personajes.

En definitiva, se ejemplifica cómo William Faulkner utiliza las tres grandes gueras mencionadas como instrumentos de composición artística ya que la estructura social, el sistema socio-económico y la esfera histórico-cultural de Yoknapatawpha están influidos por ellas notoriamente.

\section{Referencias bibliográficas}

BASSET, John (1975): William Faulkner. The Critical Heritage. London: Routledge and Kegan Paul.

BRooKs, Cleanth (1966): William Faulkner: the Yoknapatawpha Country. New Haven: Yale University Press.

- (1978): William Faulkner: Toward Yoknapatawpha and beyond. New Haven: Yale University Press. 
FAULKNER, William (1933): Sanctuary: The Corrected Text. New York: Vintage International. - (1954): A Fable. New York: Random House.

- (1964a): Absalom, Absalom! New York: Random House.

- (1964b): Soldier's Pay. Harmondsworth: Penguin in association with Chatto and Windus.

- (1964c): The Hamlet. New York: Random House.

- (1985a): Light in August. New York: Vintage International.

- (1985b): Novels 1930 - 1935. New York: Library of America Corp.

- (1995): The Sound and the Fury. London: Vintage Books.

HemingWAY, Séan (2014): Hemingway on War. London: Vintage Books.

Hines, Thomas S. (1996): William Faulkner and the Tangible Past: The Architecture of Yoknapatawpha. Los Angeles: University of California Press.

Jenkins, Philip (2012): A History of the United States. New York: Palgrave Macmillan.

Kaplan, Amy (1992): The Social Construction of American Realism. Chicago: University of Chicago Press.

LEARY, Lewis (1973): William Faulkner and Yoknapatawpha County. New York: Thomas Y. Crowell Company.

Polk, Noel (1998): Children of the Dark House: Text and Context in Faulkner. Jackson: University Press of Mississippi.

RoBERTS, Diane (1994): Faulkner and Southern Womanhood. London: University of Georgia Press.

SundQUIST, Eric J. (1983): Faulkner: The House Divided. London: Johns Hopkins University Press.

TredELL, Nicolas (1999): F. Scott Fitzgerald: «The great Gatsby». New York: Columbia University Press.

WiLliamson, Joel (1993): William Faulkner and Southern History. New York: Oxford University Press. 